\title{
Nutrient analysis of the developed low glycemic composite flour for the effective management of diabetes
}

\author{
Shimla Meena, Vimla Dunkwal and Madhu Goyal
}

\begin{abstract}
The food composition to guide food choices for better management and prevention of chronic diseases such as type 2 diabetes. Now a days most of people are consuming more refined flour or refined products, which are high in glycemic value, low in micronutrients and fibre. In India where cereals and pulses are the main sources of energy, whole grains consumption can be easily promoted through appropriate nutrition education. Diabetes is closely linked to diet and nutrition both with respect to its causation and management. All nutrition factors, either excess factor or cardohydrates, which contribute to higher intake of calories and enhance body weight have been etiologically associated with diabetes (Bamji et al., 2003). Present study was carried out to develop low glycemic composite flour for the Effective management of diebetes. The investigation was done to prepare composite flour useing Oat, Barley, Soybean, Bengal gram, Wheat and Pearl Millet in the ratio of 20:20:20:20:5:15. Nutrient analysis of control and developed composite flour revealed that moisture, crude protein, crude fat, crude fibre, ash, total carbohydrate and total energy were estimated to be 5.6 and 6.3 per cent, 11.97 and 18.48 per cent, 3.27 and 6.05 per cent, 3.0 and 5.3 per cent, 1.4 and 2.3 per cent, 70.37 and 54.26 per cent and 385.8 and $349.7 \mathrm{kcal} / 100 \mathrm{~g}$, respectively. Results of nutritional analysis observed the highly significant difference in nutrient content of both control and experimental flours.
\end{abstract}

Key Words : Diabetes mellitus, Composite flour, Nutrient, Diet, Low glycemic.

How to cite this article : Meena, Shimla, Dunkwal, Vimla and Goyal, Madhu (2018). Nutrient analysis of the developed low glycemic composite flour for the effective management of diabetes. Food Sci. Res. J., 9(1): 1-6, DOI : 10.15740/HAS/FSRJ/9.1/1-6.

\footnotetext{
Author for correspondence :

Shimla Meena, Department of Food and Nutrition, College of Home Science, S.K. Rajasthan Agricultural University, Bikaner (Rajasthan) India (Email : simmimeena4578@gmail.com)

Associate Authors' :

Vimla Dunkwal and Madhu Goyal, Department of Food and

Nutrition, College of Home Science, S.K. Rajasthan Agricultural University, Bikaner (Rajasthan) India
} 